\title{
Nanoparticle layers of CdSe buried in oxide and chalcogenide thin film matrices
}

\author{
D. Nesheva ${ }^{\mathrm{a}, *}$, H. Hofmeister ${ }^{\mathrm{b}}$, Z. Levi ${ }^{\mathrm{a}}$, Z. Aneva ${ }^{\mathrm{a}}$ \\ ${ }^{a}$ Bulgarian Academy of Sciences-Institute of Solid State Physics, 72 Tzarigradsko Chaussee Blvd., 1784 Sofia, Bulgaria \\ ${ }^{\mathrm{b}}$ Max Planck Institute of Microstructure Physics, Weinberg 2, D-06120 Halle, Germany
}

Received 15 May 2001; accepted 27 August 2001

\begin{abstract}
Nanoparticles of CdSe embedded in amorphous $\mathrm{SiO}_{x}, \mathrm{GeS}_{2}$ and polycrystalline $\mathrm{ZnSe}$ thin films have been produced by sequential physical vapour deposition of CdSe and one of the matrix materials. High-resolution electron microscopy has been used to prove the formation of CdSe nanoparticles. Particles with nearly spherical shape were observed whose spatial distribution follows the surface morphology of the 'matrix' films. The mechanism of nanoparticle formation on a rough surface has been discussed. It has been found that annealing of $\mathrm{SiO}_{x}-\mathrm{CdSe}$ films at $973 \mathrm{~K}$ leads to the formation of isolated CdSe nanoparticles homogeneously distributed in the matrix. Quantum-size increase in the optical band gap of CdSe nanoparticles has been observed in all matrices used. (C) 2002 Elsevier Science Ltd. All rights reserved.
\end{abstract}

Keywords: Physical vapor deposition; CdSe nanoparticles; High-resolution electron microscopy; Optical absorption

\section{Introduction}

Bulk composites of $\mathrm{CdS}_{x} \mathrm{Se}_{1-x}$ semiconductors and boro-silicate glasses (semiconductor doped glasses) have been the focus of intensive research because they demonstrate a high and fast optical nonlinearity interesting for signal processing or designing optical communication systems [1-3]. Moreover, these composites are suitable for studying quantum-size effects in quasi-zero dimensional systems (quantum dots) [4]. Photo- and electroluminescence of CdSe nanocrystals is also interesting for practical uses [5,6] since the wavelength of the emitted light may be changed merely by

\footnotetext{
*Corresponding author. Tel.: + 359-2-7144-226; fax: + 3592-9753-632.

E-mail address: nesheva@issp.bas.bg (D. Nesheva).
}

changing the nanocrystallite size. The preparation of doped glasses generally comprises two steps: (i) long-time fabrication of oversaturated solid solutions by co-melting of the semiconductor components with some silicate glass at high temperatures $(T \approx 1500 \mathrm{~K})$ and (ii) nanocrystallite growth at temperatures $T>900 \mathrm{~K}$ for several to $100 \mathrm{~h}$. Thin film counterparts of doped glasses have also been prepared $[7,8]$, in which the first step is co-sputtering of $\mathrm{SiO}_{2}$ and II-VI semiconductor and the second one is nanocrystallite growth at temperatures $T>900 \mathrm{~K}$.

In this article we report a successful production of CdSe nanoparticles in thin film matrices from amorphous $\mathrm{SiO}_{x}$ and $\mathrm{GeS}_{2}$ as well as polycrystalline $\mathrm{ZnSe}$ by means of a multilayer approach. The influence of annealing at various temperatures on the spatial distribution of CdSe nanocrystals is 
investigated. A mechanism of nanoparticle formation is suggested and some optical properties of the nanoparticles are described.

\section{Experimental}

Consecutive thermal evaporation of CdSe and the matrix material $\left(\mathrm{SiO}\right.$, or $\mathrm{GeS}_{2}$, or $\left.\mathrm{ZnSe}\right)$ was carried out from two independent tantalum crucibles at a vacuum of $\sim 5 \times 10^{-4}-10^{-3} \mathrm{~Pa}$ $[9,10]$. The Corning 7059 glass, quartz and c-Si substrates used were not intentionally heated. The number of layers in the samples was varied between 30 and 120 depending on their thickness. The nominal film thickness and deposition rate of both materials were controlled during deposition by two preliminary calibrated quartz monitors. CdSe layers had a nominal thickness $d_{\text {CdSe }}$ between 1 and $6 \mathrm{~nm}$ and in all samples the thickness of the 'matrix' layers was $d_{\text {matrix }}=20 d_{\mathrm{CdSe}}$ (i.e. $\left.d_{\text {matrix }}=20-120 \mathrm{~nm}\right)$. Some samples of each kind were annealed for $60-90 \mathrm{~min}$ at $673 \mathrm{~K}$. The $\mathrm{SiO}_{x^{-}}$ CdSe films were annealed in air or argon while the $\mathrm{GeS}_{2}-\mathrm{CdSe}$ and $\mathrm{ZnSe}-\mathrm{CdSe}$ films were annealed only in argon.

High-resolution electron microscopy (HREM) measurements were performed by means of a JEM 4000 EX operating at $400 \mathrm{kV}$. Electron micrographs were recorded at 40,000, 110,000 and 500,000 times magnification using optimum contrast conditions (near Scherzer defocus). The constant photocurrent method was employed $[9,11]$ in order to study the absorption of CdSe nanoparticles in the region $1.45-3.1 \mathrm{eV}$. Planar contacts from aluminum (on the $\mathrm{SiO}_{x}-\mathrm{CdSe}$ films), carbon (on the $\mathrm{GeS}_{2}-\mathrm{CdSe}$ films) and sputtered gold or In-Ga (on the $\mathrm{ZnSe}-\mathrm{CdSe}$ films) have been used in those measurements.

\section{Results and discussion}

\subsection{Nanoparticle formation}

It is well known that in the vapor deposition of materials surface roughness of layers increases with increasing film thickness [12]. In our samples, the superthin layers of CdSe are deposited on the rough surface of the relatively thick $(20-120 \mathrm{~nm})$ 'matrix' layer underneath. Hence, one can expect that CdSe superthin films in the multilayer structures described will be disrupted and nanosized regions will be formed. HREM has been used to prove the formation of CdSe nanoclusters in $\mathrm{SiO}_{x}(x \approx 1.5)$ or $\mathrm{GeS}_{2}$ matrices as well as to study their shape, size, structure and spatial distribution. Cross-sectional electron micrographs shown in Figs. 1a and 2 reveal in both $\mathrm{SiO}_{x}$ and $\mathrm{GeS}_{2}$ matrices CdSe clusters with nearly spherical shapes, which are not disposed in a plane. The spatial distribution of the clusters follows the surface morphology of the 'matrix' films. CdSe nanoparticles are partly isolated and partly in contact with each other. The higher magnification
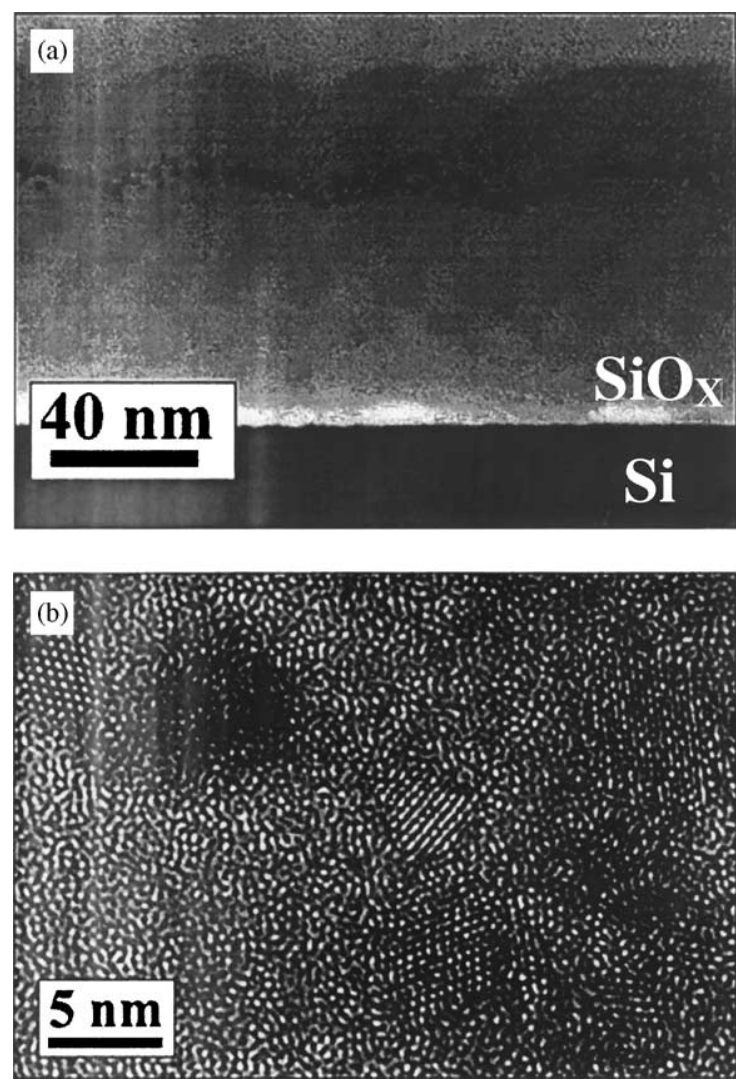

Fig. 1. Cross-section view of as-deposited $\mathrm{SiO}_{x}(40 \mathrm{~nm}) /$ $\mathrm{CdSe}(2 \mathrm{~nm}) / \mathrm{SiO}_{x}(20 \mathrm{~nm})$ three layer structure at (a) low and (b) high magnification. 


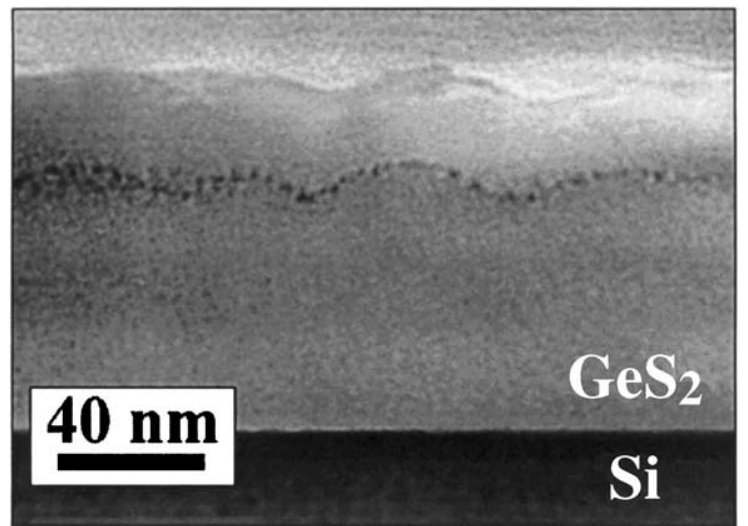

Fig. 2. Cross-section view of as-deposited $\mathrm{GeS}_{2} \quad(40 \mathrm{~nm})$ $\mathrm{CdSe}(2 \mathrm{~nm}) / \mathrm{GeS}_{2}(20 \mathrm{~nm})$ three layer structure at low magnification.

shows (Fig. 1b) that the crystal lattice of the particles is oriented randomly. The $\sigma / a$ ratio ( $a$ : average size of nanocrystals, $\sigma$ half-width at half-maximum of size distribution) found [10] for $1 \mathrm{~nm} \mathrm{CdSe}$ deposited on $20 \mathrm{~nm} \mathrm{SiO}_{x}$ is 0.13 , while for $2 \mathrm{~nm}$ CdSe deposited on $40 \mathrm{~nm} \mathrm{SiO}_{x}$ it is 0.19 .

Nonepitaxial self-organized metal nanocluster formation has been reported $[13,14]$ on the rough surface of amorphous $\mathrm{Si}: \mathrm{H}$ and $\mathrm{SiO}_{x}$ thin films deposited by means of vapor deposition or glowdischarge techniques. Mo and $\mathrm{W}$ nanoparticles arranged in chains with up to several hundred nanometers length and sizes much greater than the deposited nominal metal layer thickness have been observed [13]. Moreover, $\mathrm{ZnCdSe}$ quantum dots were fabricated with a two-chamber molecular beam epitaxy system on $\mathrm{ZnSe}$ crystalline films of deliberate surface roughness [15]. The mechanism of nanoparticle formation on a rough surface is not clear. The Stranski-Krastanow self-organized epitaxial growth in strained systems, which takes place on the smooth surface of crystalline materials, could not be invoked to explain nanoparticle growth on a rough surface. Mechanisms such as partial wetting of $\mathrm{Ga}$ with respect to $\mathrm{SiO}_{x}[14]$ and filling up the existing valleys of the thin film a-Si:H surface [13] were considered as being responsible for the nanoparticle formation.

It is known [12] that at the first stage of thin film deposition on a rough surface an embryo forma- tion takes place, which depends on many factors such as the temperature, chemical nature, smoothness and cleanness of the substrate surface. In particular, the presence of steps or other defects on the substrate surface leads to an increase in the embryo concentration. Also, it has been shown [16] that the curvature and stress at a rough surface strongly affect reaction rates at a solid interface because of the existence of different environments at different reaction sites. It is seen from Figs. 1a and 2 that the spatial distribution of the CdSe particles follows the surface morphology of the $\mathrm{SiO}_{x}$ and $\mathrm{GeS}_{2}$ films. This allows us to assume that, independently on the chemical nature of the surface, at the very beginning of CdSe film deposition embryos are formed at those surface positions at which the curvature and lattice stress are the greatest. The relatively narrow nanocluster size distribution observed [10] indicates that most likely further CdSe deposition does not create new embryos, but increases only the size of already existing nanoparticles. Figs.1a and b show that at low substrate temperatures and a thickness ratio of $d_{\text {matrix }} / d_{\mathrm{CdSe}}=20$ the surface roughness of the 'matrix' layers is sufficient to ensure the formation of quasi-isolated CdSe nanoparticles. However, multilayer structures fabricated as described above, but having a thickness ratio $d_{\text {matrix }} / d_{\mathrm{CdSe}} \approx 1 \quad(d=2-10 \mathrm{~nm})$ and a smooth surface of the 'matrix' layers behave as high quality amorphous/nanocrystalline multiple quantum wells $[11,17,18]$. These results prove the correctness of the suggested mechanism of selforganized nanocluster formation on a rough surface and indicate that the multilayer vapor deposition technique may be applied for fabrication of both II-VI nanoclusters in various matrices and multiple quantum well structures from various materials.

\subsection{Annealing induced changes}

Annealing of $\mathrm{SiO}_{x}\left(\mathrm{GeS}_{2}, \mathrm{ZnSe}\right)-\mathrm{CdSe}$ composite films for $60-90 \mathrm{~min}$ at $673 \mathrm{~K}$ in air or argon differently affects the nanoparticle/matrix interface structure and nanoparticle composition. Only a minor increase of particle size has been observed in the $\mathrm{SiO}_{x}-\mathrm{CdSe}$ films accompanied by an improve- 
ment of the spherical appearance and crystallinity of the CdSe nanoparticles [10]. In the films with a chalcogenide matrix $\left(\mathrm{GeS}_{2}(\mathrm{ZnSe})-\mathrm{CdSe}\right)$ an appreciable material intermixing occurs at the interface even in as-deposited films and strong further alloying takes place upon annealing [19]. This alloying has been related to diffusion of $\mathrm{Cd}$ atoms from CdSe nanoparticles into the $\mathrm{GeS}_{2}(\mathrm{ZnSe})$ matrix. Because of this material intermixing in $\mathrm{GeS}_{2}(\mathrm{ZnSe})-\mathrm{CdSe}$ films, the effect of annealing at high temperatures $(>673 \mathrm{~K})$ on size and spatial distribution of CdSe nanoparticles has been studied only in $\mathrm{SiO}_{x}-\mathrm{CdSe}$ films. Samples with nominal CdSe layer thickness of 1 and $2 \mathrm{~nm}$ were annealed at $873 \mathrm{~K}$ for $10 \mathrm{~min}$ and $973 \mathrm{~K}$ for $30 \mathrm{~min}$. The annealing at $873 \mathrm{~K}$ did not induce appreciable changes in both size and spatial distribution. However, the cross-section view of a $\mathrm{SiO}_{x} / \mathrm{CdSe} /$ $\mathrm{SiO}_{x}$ three layer structure annealed at $973 \mathrm{~K}$ in argon (Fig. 3) reveals a spatial arrangement of the CdSe particles, which is completely different from that shown in Figs. 1 and 2. The three-layer structure is no longer observed. Instead, mainly small-sized nanoparticles ( $\sim 2 \mathrm{~nm}$ in diameter) homogeneously distributed in the $\mathrm{SiO}_{x}$ matrix are seen in the micrograph. Obviously, the annealing of $\mathrm{SiO}_{x}-\mathrm{CdSe}$ films at $973 \mathrm{~K}$ causes dissolution of the CdSe nanoparticle layer followed by a homogeneous material distribution within the whole $\mathrm{SiO}_{x}$ matrix and nanoparticle re-

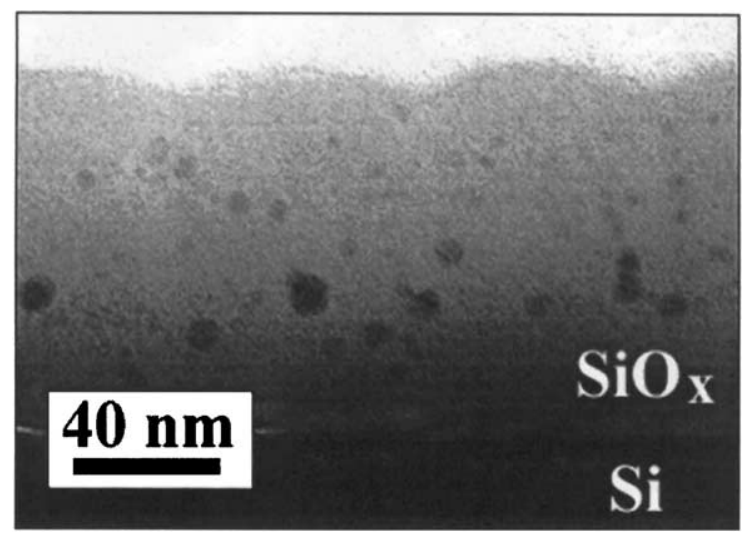

Fig. 3. Cross-section view of the spatial arrangement of CdSe nanoparticles in a $\mathrm{SiO}_{x}(40 \mathrm{~nm}) / \mathrm{CdSe}(2 \mathrm{~nm}) / \mathrm{SiO}_{x}(20 \mathrm{~nm})$ three layer structure annealed in argon at $973 \mathrm{~K}$ for $30 \mathrm{~min}$. growth. Investigations of $\mathrm{CdS}_{x} \mathrm{Se}_{1-x}$ doped borosilicate and $\mathrm{SiO}_{2}$ matrices $[7,8,20]$ show that $\mathrm{CdSe}$ nanoparticle growth in a $\mathrm{SiO}_{x}$ matrix is rather quick. This result may be connected with the existence of both concentration gradient in the CdSe spatial distribution and a high concentration of structural defects which facilitates $\mathrm{Cd}$ and $\mathrm{Se}$ atom diffusion.

\subsection{Electronic and optical properties}

Semiconductor nanoparticles represent a class of quasi-zero dimensional objects or quantum dots in which due to carrier confinement molecular-like discrete spectra are observed. Thus the energy gap of semiconductor nanocrystals can be tuned merely by changing their size. Optical transmission and absorption spectra were measured on $\mathrm{SiO}_{x}$ $\left(\mathrm{GeS}_{2}, \mathrm{ZnSe}\right)-\mathrm{CdSe}$ films in order to study the electronic structure of CdSe nanoparticles. Peculiarities in the transmission spectra (not shown here) of all kinds of composite films were observed at energies higher than the optical band gap of bulk CdSe. They indicated a band gap increase with decreasing nanocrystallite size. Photocurrent measurements were carried out in order to measure absorption spectra of CdSe nanoparticles with higher accuracy than that of the transmission measurements. The energy dependences of the absorption coefficient of $\mathrm{CdSe}$ nanocrystals in $\mathrm{SiO}_{x}\left(\mathrm{GeS}_{2}, \mathrm{ZnSe}\right)$ composite films are presented in Fig. 4. A substructure is seen in the absorption spectra, which may be related to electron transitions between different energy levels in the valence and conduction bands of CdSe nanocrystals [4]. The energy corresponding to transitions between the highest valence band and lowest conduction band levels (which define the optical gap $E_{\mathrm{g}}$ of CdSe nanoparticles) is between 1.95 and $2.0 \mathrm{eV}$. This value is higher than the optical gap $(1.75 \mathrm{eV})$ of CdSe crystals, which proves that in all matrices CdSe quantum dots have been successfully produced. It is interesting to notice that very similar optical gap values (see Fig. 4) have been obtained for CdSe nanoparticles in matrices having different optical gaps $\left(\mathrm{SiO}_{x}-x \approx 1.5, \quad E_{\mathrm{g}}=2.9 \mathrm{eV}\right.$; $\left.\mathrm{GeS}_{2}-E_{\mathrm{g}}=2.5 \mathrm{eV} ; \mathrm{ZnSe}-E_{\mathrm{g}}=2.6 \mathrm{eV}\right)$ and con- 


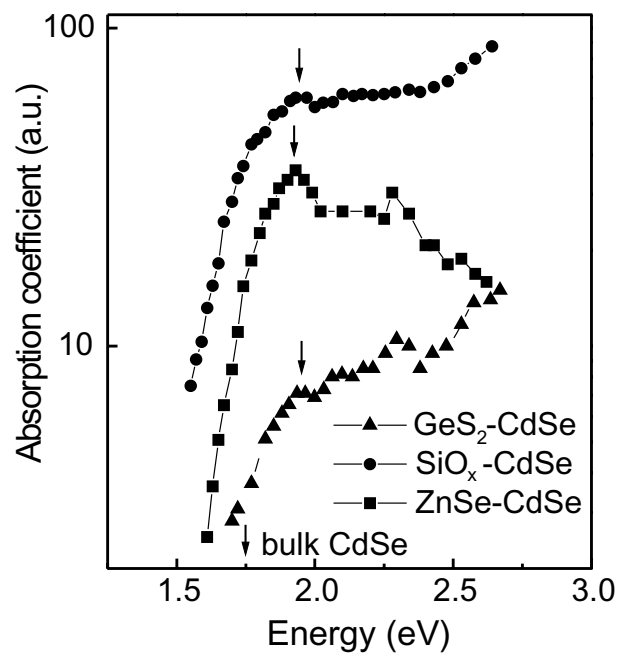

Fig. 4. Absorption coefficient of as-deposited $\mathrm{SiO}_{x}-\mathrm{CdSe}$, $\mathrm{GeS}_{2}-\mathrm{CdSe}, \mathrm{ZnSe}-\mathrm{CdSe}$ composite films in which CdSe layers have a nominal thickness of $5 \mathrm{~nm}$. The arrows in the figure denote optical band gaps of bulk CdSe and CdSe nanoparticles in the respective matrix.

ductivity type $\left(\mathrm{SiO}_{x}\right.$ and $\mathrm{ZnSe}$ are n-type semiconductors while $\mathrm{GeS}_{2}$ is p-type).

\section{Conclusion}

The fabrication of discontinuous CdSe nanoparticle layers by physical vapor deposition of $\mathrm{CdSe}$ on rough surface of amorphous $\mathrm{SiO}_{x}$ and $\mathrm{GeS}_{2}$ and polycrystalline $\mathrm{ZnSe}$ films has been reported. For the amorphous $\mathrm{SiO}_{x}, \mathrm{GeS}_{2}$ matrices the existence of nearly spherical nanoparticles has been proved by HREM studies and a relatively narrow particle size distribution has been established. Annealing of $\mathrm{SiO}_{x}-\mathrm{CdSe}$ films at $973 \mathrm{~K}$ leads to the formation of isolated CdSe nanoparticles homogeneously distributed within the whole $\mathrm{SiO}_{x}$ matrix. Quantum-size increase in the optical band gap of CdSe nanoparticles has been observed in all matrices. Hence, the described multilayer vapor deposition technique allows fabrication of
II-VI quantum dots in various matrices. In oxide matrices either contacting or isolated nanoparticles can be prepared.

\section{References}

[1] Jain RK, Lind RC. J Opt Soc Am 1983;73:647-53.

[2] Vanhaudenarde A, Trespidi M. J Opt Soc Am B 1994;11:1474-9.

[3] Flytzanis C, Ricard D, Schanne-Klein MC. J Lumin 1996;70:212-21.

[4] Ekimov AI, Hache F, Schanne-Klein MC, Ricard D, Flytzanis C, Kudryavtsev IA, Yazeva TV, Rodina AV, Efros AlL. J Opt Soc Am B 1993;10:100-7.

[5] Dabbousi BO, Rodriguez-Viejo J, Mikulic FV, Heine JR, Mattoussi H, Ober R, Jensen KF, Bawendi MG. J Phys Chem B 1997;101:9463-75.

[6] Rodriguez-Viejo J, Mattoussi H, Heine JR, Kuno MK, Michel J, Bawendi MG, Jensen KF. J Appl Phys 2000;87:8526-34.

[7] Tsunemoto K, Kawabuchi A, Kitayama H, Osaka Y, Nasu H. Jpn J Appl Phys 1990;29:2481-6.

[8] Gurevich SA, Ekimov AI, Kudryavtsev IA, Lyubinskaya OG, Osinskii AV, Usikov AS, Faleev NN. Sov Phys Semicond 1994;28:830-43.

[9] Nesheva D, Levi Z. Semicond Sci Technol 1997;12:131922.

[10] Nesheva D, Hofmeister H. Solid State Commun 2000;114:511-4.

[11] Nesheva D, Levi Z, Hofmeister H, Aneva Z, Nikolova V. J Phys: Condens Matt 2000;12:751-9.

[12] Chopra KL. Electrical phenomena in thin films. Moskwa: Mir, 1972.

[13] Drüsedau TP, Panckow AN, Klabunde F. J Non-Cryst Solids 1996;198-200:829-32.

[14] Tonova D, Patrin M, Tognini P, Stella A, Cheyssac P, Kofman R. J Phys: Condens Matter 1999;11:2211-22.

[15] Zhang BP, Yasuda T, Segawa Y, Yaguchi H, Onabe K, Edamatsu E, Itoh T. Appl Phys Lett 1997;70:2413-5.

[16] Tersoff J, Tu Yu, Grinstein G. Appl Phys Lett 1998;73:2328-30.

[17] Nesheva D, Raptis C, Levi Z. Phys Rev B 1998;58: 7913-20.

[18] Popescu M, Sava F, Lorinczi A, Vateva E, Nesheva D, Tschaushev G, Mihailescu IN, Koch P-J, Obst S, Bradaczeck H. Proc SPIE 1998;3405:964-8.

[19] Nesheva D, Raptis C, Levi Z, Bineva I, Aneva Z. Asian J Phys 2000;9:289-98.

[20] Rodden WSO, Ironside CN, Sotomayor Torres CM. Semicond Sci Technol 1994;9:1839-42. 